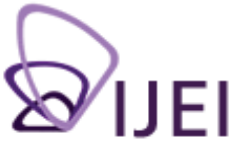

\author{
International \\ Journal for \\ Educational \\ Integrity
}

\title{
Review \\ Ethics of internet research: A rhetorical case-based approach
}

\author{
Heidi McKee and James Porter (2009) \\ New York, NY: Peter Lang
}

\author{
Andrew Whelan \\ School of Social Sciences, Media and Communication \\ University of Wollongong \\ andrew_whelan@uow.edu.au
}

\section{Review}

Ethics of Internet Research is the $59^{\text {th }}$ volume in the Digital Formations series published by Peter Lang and the first volume in that series dedicated to research ethics, a subject not substantively addressed by Digital Formations since 2003's Online Social Research. It is a good companion piece to Digital Media Ethics by Charles Ess, also released in 2009 but published by Polity Press, which concentrates on more 'structural' issues, such as copyright.

As the subtitle suggests, Ethics of Internet Research advocates for online research ethics grounded in rhetoric, and in casuistry, terms which may be relatively unfamiliar in this context to those trained in more traditional social research methods and institutional contexts oriented to 'human subjects'. The co-authors both teach in composition and rhetoric, although they have research interests in internet research and digital media. Their disciplinary alignment flavours the argument, although scholars in anthropology, sociology, digital communications and elsewhere are likely to find the book helpful. As evinced by the references, the Foreword, and the researchers interviewed in the text, the authors are involved in the (largely American) milieu of the interdisciplinary Association of Internet Researchers.

Discussions of online research ethics customarily take one of two tacks: the authors may begin by interrogating the ways online material of the sort they have approached is, in ethical terms, like or unlike either text or communicative interaction, and proceed accordingly. Text is ethically 'inert', barring appropriate citation of the original authors, whilst interaction or communication involves human subjects and their ethical entitlements. Sometimes this binary disjuncture is played out in different terms, framed with regard to 'public' (approximately analogous to text) and 'private' (approximately analogous to interaction). Here, ethical orientation is aligned with respect to privacy and/or the obligation to secure informed consent (prospectively or retrospectively, although this rather cloudy issue is often overlooked). Alternatively, the researchers may outline 'classical' positions in philosophical ethics (consequentialist, deontological, aretaic and so on) and discuss how these frameworks may or may not be applied to the forms of online material researched and the manner in which the research was accomplished.

Although McKee and Porter range across these orientations and frequently reproduce these binaries (setting them at one point as space-medium-text vs. place-communityperson), for the most part they argue for a 'sliding scale' rather than an 'either-or'

The International Journal for Educational Integrity is available online at:

http://www.ojs.unisa.edu.au/journals/index.php/lJEl/

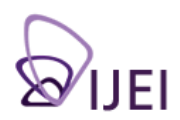


orientation. Their objective in doing so is to provide practical guidance to internet researchers, and their approach is generally pragmatic and productive. As they point out, there is a wide variety of contemporary phenomena which is neither text nor selfevidently human interaction (for example, Second Life avatars, and their relations with each other and their operators, for want of a better word), just as there are locations (such as Facebook pages) which are neither public or private in the senses in which these terms are generally understood (particularly in more established approaches to mass communication). Even seemingly stable forms of online communication - blogs, for instance - vary hugely in their composition, uses, and the understandings participants articulate about what sort of communication is occurring, where, and what may be done with it. People may share personal information openly, and nonetheless vehemently oppose that information being used for research purposes. Furthermore, a bewildering array of ethical considerations may (and often does) become salient for scholars in the course of their research.

Part of the objective for the authors is thus to unsettle customary and predictable orientations to research ethics online, and to thereby raise rather than answer (and thus close) questions. At times this makes for somewhat frustrating reading, as the text descends into sequences of unanswered rhetorical questions; an irritating stylistic tic. At other times, however, the authors do well to interrogate the institutional frameworks in which research ethics are customarily articulated. Institutional clearance for a given research project is not only a bureaucratic hurdle, it also invites an understanding that because the institution says the research is ethical, it is. This can abnegate scholars' individual ethical relationships with their field site and their research participants. Aside from this moral imperative and the potential for its institutional elision, ethics committees, in the US as elsewhere, generally structure their understandings of ethical research on medical models. In their chapter on 'regulatory ethics', McKee and Porter present an engaging discussion of a decision chart produced by the Office for Human Research Protections, pointing out the disconcerting alacrity with which many now conventional approaches to gathering data online literally fall off the ethical chart (much of what is of value in this book actually consists of visual heuristics useful to think through for active researchers). They also discuss a range of issues which warrant attention but may not be immediately evident to researchers: copyright, cultural variation, how different national regulatory frameworks may impinge on research (although they are oriented to the US in particular), and how specific research contexts and projects entail specific ethical orientations.

Effectively, this is the crux of their argument - that there is no one-size-fits-all orientation to ethical online research. In different contexts different ethical arguments may be trumped, and researchers would be wise to consider, in a consistent, ongoing, iterative and holistic way, the ramifications of their actions, and the ramifications of their actions for a wide range of audiences (participants in the research, readers of the research, people who occupy similar online environments to those researched, but perhaps in different countries or cultures, future researchers and participants in such environments, the list goes on). Scholars have a meta-ethical obligation, in a sense, to be attentive to the ethical specificities of their own research, as that research develops.

Curiously, the authors at no point reflect on their own ethical position, as people who have published a book based on interviews with online researchers, many of whom have evidently thought very deeply - or, indeed, agonised - about complex ethical issues in their research, including issues where the safety and wellbeing of their research subjects seemed to be at risk. This lacuna is all the more perplexing given the authors' interest in pluralist and reflexive ethical practice, and in undermining binaries (such as, presumably, online/offline). 
Concerns about appropriate ethical frameworks for online research are unlikely to dissipate. It is dawning on humanities and education faculties everywhere that online research is cheap, as well as being an extremely dynamic emerging field. Online environments, in a way, present a sort of final frontier, where scholars at the postmodern university may encounter an Other at once intimately familiar and yet still perplexingly unlike 'the real' of everyday offline life. The emergent field of internet research ethics is increasingly addressed thoughtfully among scholars online, and as of yet rather less so in print. McKee and Porter have produced an informed and pragmatic contribution to this field.

\section{References}

Ess, C. (2009). Digital Media Ethics. Cambridge UK and Malden MA: Polity Press.

\section{Reviewer}

Andrew Whelan lectures in Sociology in the Faculty of Arts at the University of Wollongong. Before coming to UOW, Andrew taught into Gender and Popular Culture, Race and Popular Music, the Sociology of Health and IIIness, and other topics in sociology at Trinity College in Dublin, where he was awarded a PhD in 2007. He received a BA Hons in PPE from Somerville College, Oxford, in 2001. His doctoral research, published in 2008 as a monograph entitled Breakcore: Identity and Interaction on Peer-to-Peer, addressed sampling practices, gender, and online interaction in a musical subculture, and he has published papers since on anthropological theory and file-sharing, breakbeats, and 'extreme' genres of music and their online distribution. He has research interests in contemporary music-based subcultures; language and identity in interaction; social and anthropological theory; and ethnomethodology. He is currently engaged in a project investigating the history of Australian independent music scenes. 